\title{
DEL OBJETO AL CONTEXTO: LA(S) CAPA(S) "E" DE HUACHICHOCANA III
}

\author{
FROM OBJECT TO CONTEXT: THE “E” LAYER(S) \\ OF HUACHICHOCANA III
}

\author{
Verónica S. Lema ${ }^{1}$
}

\begin{abstract}
El objetivo de este trabajo es realizar una puesta al día acerca de lo que hoy sabemos sobre las ocupaciones de la cueva III de Huachichocana (Jujuy, Argentina) para el período que va desde inicios del Holoceno Temprano hasta el Formativo. Los materiales analizados corresponden a las investigaciones realizadas en la localidad homónima en la década de 1970. A partir del estudio de la colección arqueológica y la bibliografía correspondiente, se procuró ir más allá de la descripción capa-objeto, preponderante en la bibliografía consultada, evaluando la posibilidad de detectar asociaciones que indiquen áreas de actividades múltiples o específicas, que nos permitan caracterizar las ocupaciones de esta cueva, a la vez que re-evaluar los contextos funerarios. Dentro de esta reconstrucción también se atendió a la reasignación de cronologías a los materiales y a la posibilidad de que elementos originalmente informados como propios de un nivel/subcapa/período pertenezcan a otro. Se informan nuevos fechados radiocarbónicos y análisis específicos sobre diversos materiales.
\end{abstract}

Palabras claves: Huachichocana, Noroeste de Argentina, Holoceno Temprano, Formativo.

The aim of this paper is to update our knowledge of the occupations at Huachichocana cave III (Jujuy, Argentina) during the time span ranging from the beginning of the Early Holocene to the Formative. The analysed remains correspond to studies carried out in the Huachichocana locality during the 1970s. From the study of the archaeological collection and of the associated bibliography, an attempt was made to go beyond the prevailing layer-object description present in the bibliography consulted, assessing the possibility of detecting associations which point out areas of multiple or specific activities, allowing us to characterize the past occupations of this cave, and also to re-evaluate the funerary contexts. Also, the reassignment of new chronologies to some materials was considered in this reconstruction, as well as the possibility that some elements originally informed as belonging to a certain level/layer/period belonged to another. New radiocarbon dates and specific analyses are also informed.

Key words: Huachichocana, Argentinian North West, Early Holocene, Formative.

Este trabajo es el resultado del análisis de la colección de la localidad arqueológica de Huachichocana (Departamento de Tumbaya, Jujuy), conformada a partir de distintas instancias de trabajo de campo realizadas por Alicia Fernández Distel en la década de 1970. Dicho análisis se realizó junto a una compilación y lectura crítica de las publicaciones referidas a esta colección, la cual se encuentra en el Museo Eduardo Casanova del Instituto Interdisciplinario Tilcara (IIT, FFyLUBA). El objetivo de este trabajo es realizar una puesta al día acerca de lo que hoy sabemos sobre las ocupaciones de la cueva III de Huachichocana (CH III) para el período comprendido entre inicios del Holoceno Temprano hasta momentos correspondientes al período Formativo dentro del Holoceno Tardío (ca. 10000-1500 a.p.). Para alcanzar dicho objetivo procuramos ir más allá de la descripción capa-objeto, preponderante en la bibliografía consultada, evaluando la posibilidad de detectar asociaciones que indiquen áreas de actividades múltiples o específicas, que nos permitan caracterizar las ocupaciones de esta cueva, a la vez que re-evaluar los contextos funerarios. En este sentido resultó esencial la realización de nuevos fechados radiocarbónicos sobre materiales de la colección y una re-evaluación de los restos recuperados a la luz de los avances que se han hecho en la arqueología regional en las últimas décadas, al igual que contar con libretas y esquemas de las excavaciones originales, aun inéditos.

\section{Antecedentes}

Luego del paso de Eric Boman y de Erland Nordenskiold a principios del siglo XX, las

1 Laboratorio de Etnobotánica y Botánica Aplicada, Facultad de Ciencias Naturales y Museo, Universidad Nacional de La Plata-Consejo Nacional de Investigaciones Científicas y Técnicas. Paseo del Bosque s/n CP 1900 La Plata, Buenos Aires, Argentina.vslema@gmail.com 
investigaciones realizadas por Alicia Fernández Distel entre 1970 y 1980 (Aguerre et al. 1975; Fernández Distel 1974, 1981, 1986; entre otros), produjeron un vasto corpus de información acerca de la variabilidad arqueológica que se encuentra distribuida en toda la quebrada de Huachichocana, destacándose las cinco cuevas homónimas y paneles con motivos pintados de diversa cronología. De estas cuevas, la III no solo es la de mayor tamaño, sino la que arrojó la secuencia de ocupación más completa, desde inicios del Holoceno hasta momentos de contacto HispanoIndígena. De acuerdo con Fernández Distel (1974, 1981, 1986), la cueva mide 14 x $8 \mathrm{~m}$ de planta y 8 $\mathrm{m}$ de altura, ubicándose a $12 \mathrm{~m}$ de altura por sobre el río de Huachichocana, sobre una terraza fluvial (Figura 1a, b). Las excavaciones se iniciaron en 1971 con un sondeo en el sector noreste, cercano a la pared rocosa y al vestíbulo, donde se definieron seis capas naturales (A-F), una de las cuales (E) se dividió en tres subcapas artificiales (E1, E2 y E3) debido a su potencia y riqueza de hallazgos (Figura 1b, c). Al año siguiente el sondeo se prolongó hacia el fondo de la cueva en una trinchera de $2 \mathrm{~m}$ de ancho por $4 \mathrm{~m}$ de largo. El corte de la trinchera fue avanzando por secciones de $1 \times 2 \mathrm{~m}$, numerados desde la línea de base de la cueva y hacia el fondo de manera correlativa con un eje ideal que dividía a cada rectángulo en dos partes: A y B. En la sección/ cuadrícula 4A se descubre a 1,7 $\mathrm{m}$ de profundidad, en la subcapa E3, una inhumación (entierro 2) y, a su izquierda, un potente fogón. Dado que la inhumación-fogón se continuaba hacia la derecha por fuera de la trinchera, se abrió el corte en forma de " $L$ " y finalmente se levantó todo el sedimento que se mantenía como testigo sobre la pared de la cueva, sección que pasó a ser denominada "C" (Figura 1b, d). La disposición de sedimentos en esta cueva sigue las marcadas pendientes que la misma posee, principalmente desde el fondo hacia la línea de goteo, de manera que las capas naturales montan y se estrechan hacia el fondo y hacia la pared izquierda, al oeste de la cueva, donde también se concentra una gran cantidad de lajas de desprendimiento de la roca de caja (Figura 1b). La mayor acumulación de sedimento se da en el ángulo este de la cueva, donde las excavaciones llegaron a una profundidad de entre 3,5 y 4,5 m. Además de la trinchera antes descrita, la investigadora menciona que se realizaron pequeños pozos de sondeo en puntos diversos de la cueva para extraer sedimento. Actualmente el vestíbulo de la cueva en su sector oriental se encuentra bajo un gran derrumbe producto de un rayo que impactó la entrada hace casi dos décadas, según testimonio de las personas de la comunidad aborigen de Huachichocana (Figura 1e, f).

Tras sucesivas campañas de excavación, el pormenorizado análisis de los elementos recuperados y la realización de seis fechados radiocarbónicos (Tabla 1), las distintas capas fueron asociadas a momentos cronológicos y períodos particulares, destacándose la más profunda con evidencias de ocupación humana (capa E) por su notable antigüedad (10.000 a.p.) y la presencia de restos de especies vegetales domesticadas (principalmente maíz) asociados a la misma (Fernández Distel 1981,1986). Es por ello que dicha capa y los hallazgos que le corresponden han sido el objeto principal de nuestras indagaciones, particularmente el entierro de un joven individuo que en su momento pasó a ser conocido como "el chamán" (Fernández Distel 1981,1986, Casiraghi 1985; bajo este nombre figura también el material en la colección).

\section{Notas Metodológicas acerca del Armado de este Trabajo}

El trabajo realizado en los depósitos del Museo Eduardo Casanova abarcó el registro completo de la colección de la localidad, tanto los restos de las cuevas I a V como los correspondientes a los abrigos rocosos de León Huasi ubicados a escasos kilómetros, en la cabecera de la quebrada, en piso de puna (Fernández Distel 1989) y sitios menores en quebradas accesorias a la de Huachichocana.

Durante nuestro trabajo notamos que algunas piezas cuentan con número de registro institucional y otras se encuentran aún en proceso de que se le asigne el mismo, por ende en el primer caso optamos por consignar el número de pieza antecedido por la sigla del instituto (por ejemplo: IIT 4507) y en el segundo hemos registrado la pieza como "sin datos" (SD, refiriendo a que no tiene datos de catalogación institucional) y un número correlativo (por ejemplo: SD 26) ${ }^{1}$.

El registro de la colección de las cuevas I a IV de Huachichocana sumó casi tres mil objetos (entre artefactos y ecofactos); de estos, 2.762 corresponden a la cueva III y 944 a la capa E. Tras el re-estudio de la colección cotejada con la bibliografía disponible, se cuenta con 113 objetos para la subcapa E1; subcapa E2 de 326 y subcapa E3 de 441, y 64 quedaron registradas como capa 

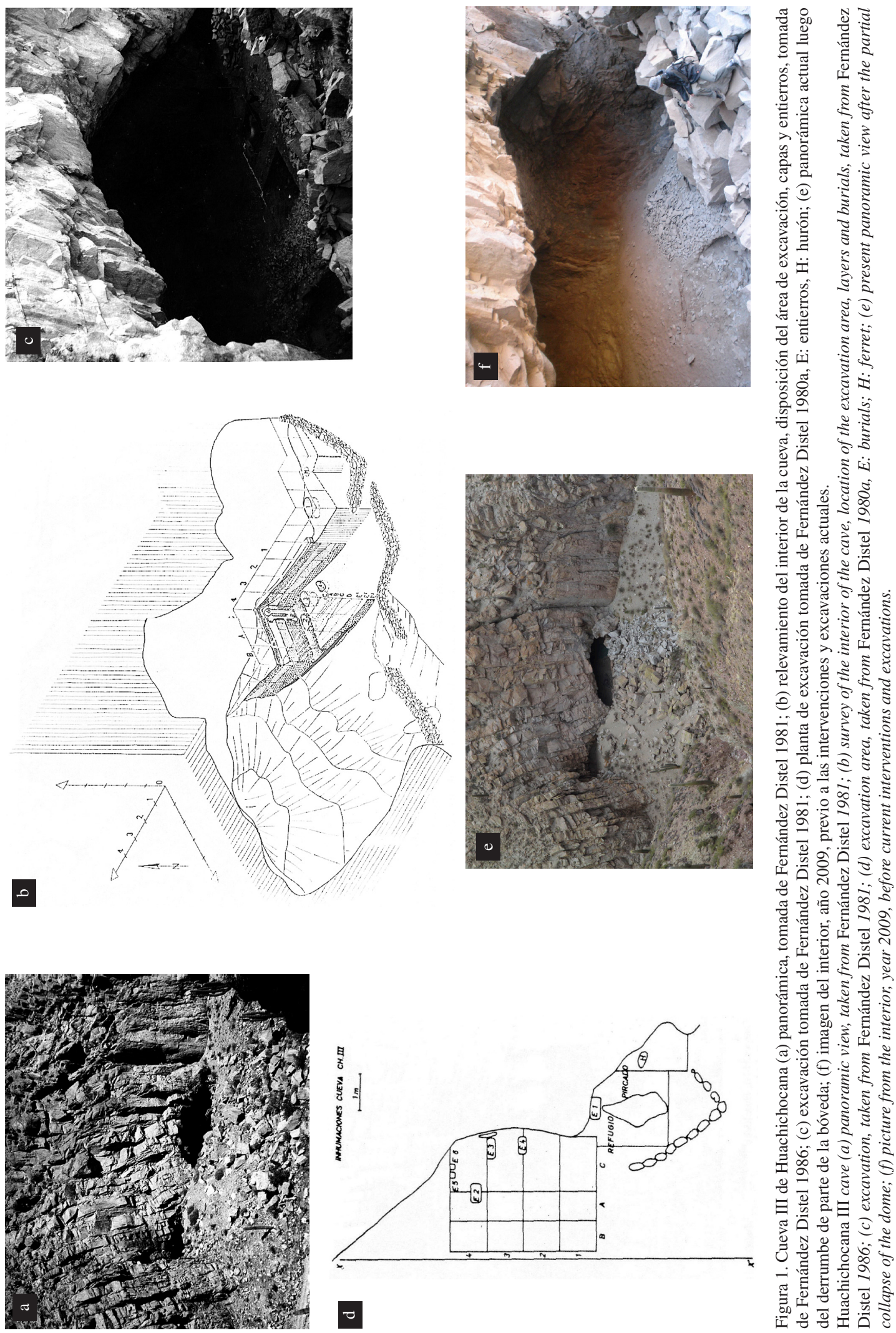


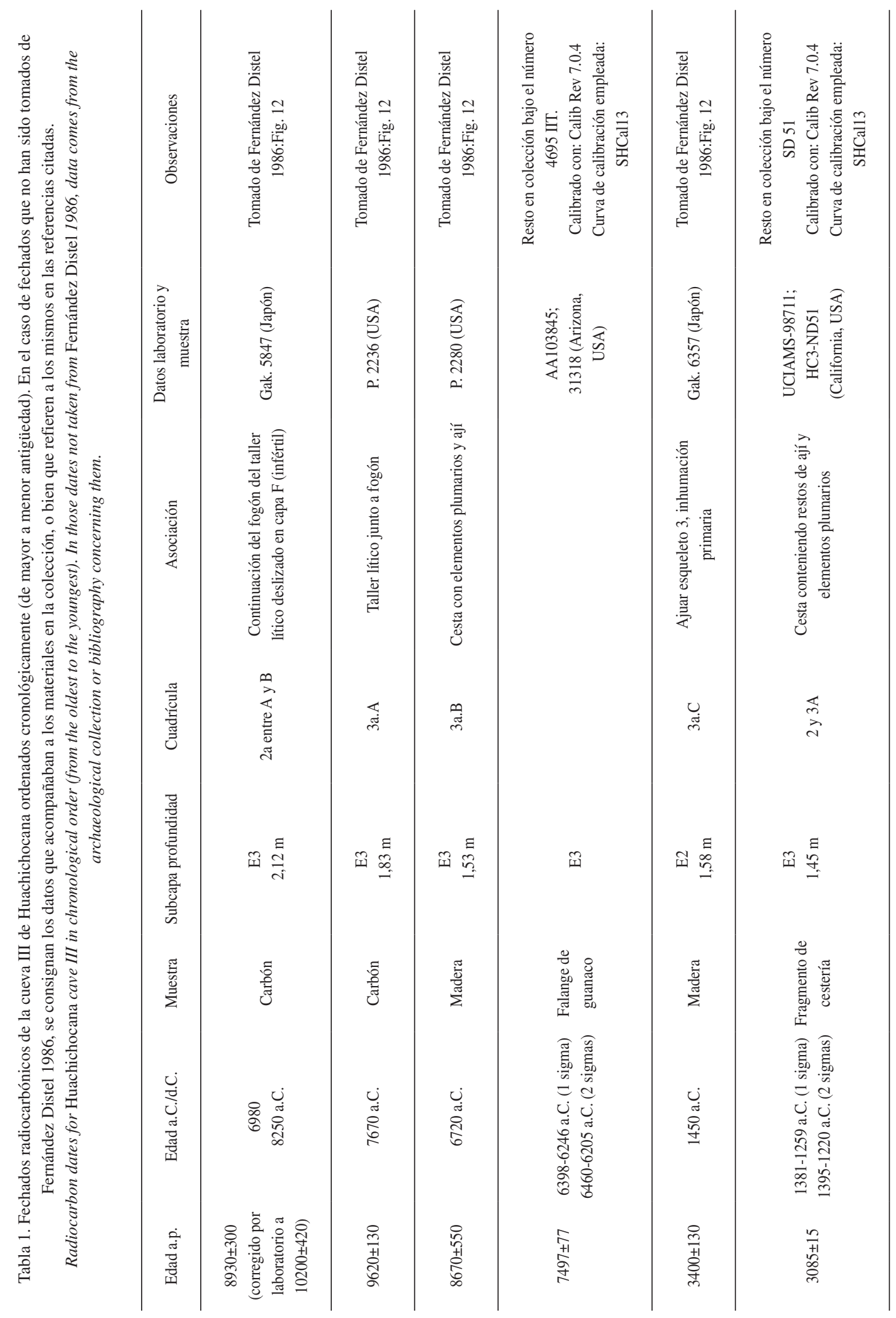




\begin{tabular}{|c|c|c|c|}
\hline 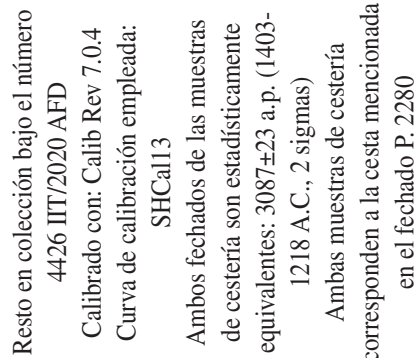 & 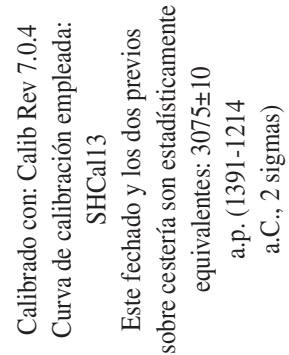 & 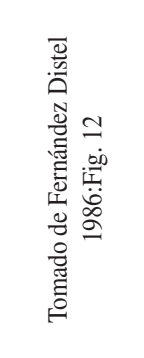 & 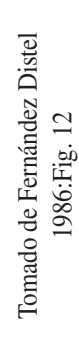 \\
\hline 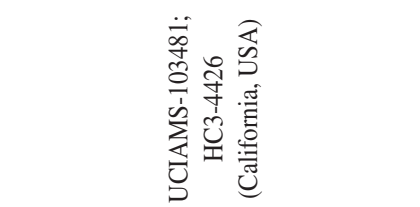 & 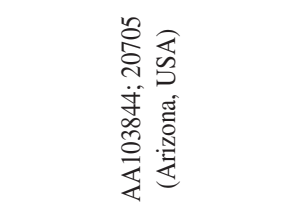 & 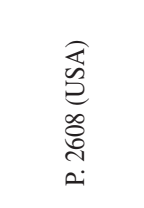 & 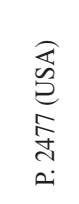 \\
\hline 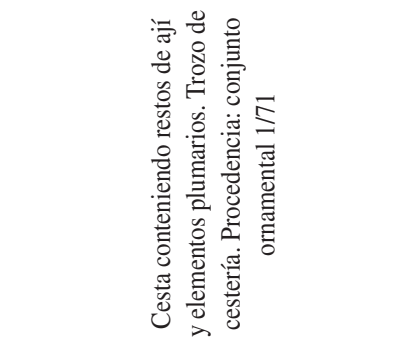 & 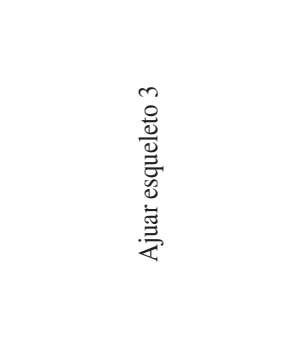 & 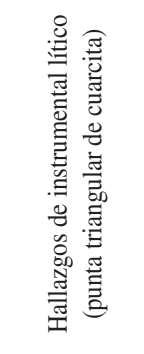 & 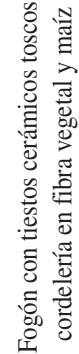 \\
\hline 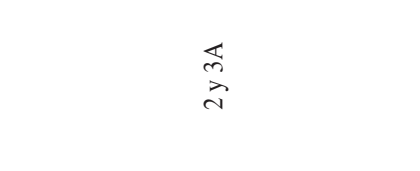 & & లే & 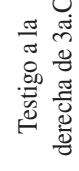 \\
\hline m & ్ㅗ & $\stackrel{\Xi}{\stackrel{\Xi}{f}}$ & 포 \\
\hline 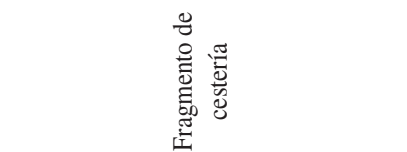 & 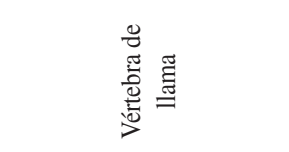 & 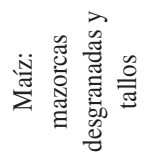 & 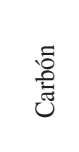 \\
\hline 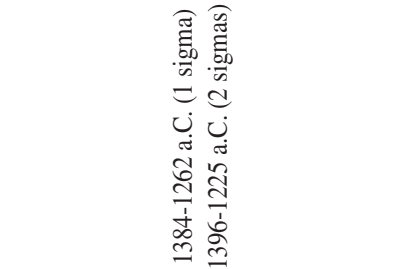 & 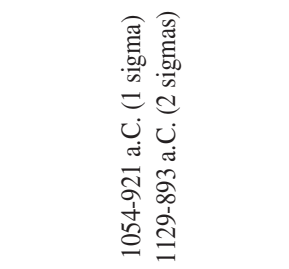 & $\begin{array}{l}\dot{u} \\
\text { jं } \\
\text { ᄋ }\end{array}$ & $\begin{array}{l}\dot{j} \\
\dot{0} \\
\text { 品 }\end{array}$ \\
\hline $\begin{array}{l}n \\
\frac{n}{+1} \\
\text { o } \\
\text { d }\end{array}$ & 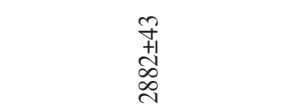 & $\begin{array}{l}8 \\
\frac{5}{+1} \\
0 \\
0\end{array}$ & 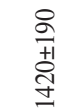 \\
\hline
\end{tabular}


E, ya que no se pudo confirmar su adscripción a alguna subcapa.

\section{La(s) Capa(s) E}

Como ya mencionamos, Fernández Distel (19721989, 1974, 1980a, 1981, 1986 y otros) subdividió la capa E (la más profunda de todas con restos culturales, ya que la F no reportó hallazgos, salvo unos pocos deslizados desde la capa $\mathrm{E}$ suprayacente) en tres subcapas o niveles artificiales: E1, E2 y E3 desde la más superficial a la más profunda. Además de las particularidades propias de cada subcapa, las cuales iremos desglosando a continuación, debe considerarse el sistema de excavación empleado, principalmente los niveles de referencia para la toma de profundidades, los cuales aparentemente no fueron los mismos en el eje $\mathrm{X}$ (que va desde el fondo hacia la entrada de la cueva: Figura 1b, d) que en el eje transversal al mismo. Por lo tanto, considerando este factor, y dadas las pendientes e inclinaciones que posee la cueva, las profundidades consignadas para los hallazgos (tanto en las etiquetas que acompañan a los materiales de la colección, en los trabajos publicados como en las notas de campo inéditas) deben considerarse con cautela a la hora de ser comparados entre sí.

\section{La subcapa E1}

Se caracterizó como de arena y pedregullo con restos vegetales y bosta de camélidos, teniendo leves fogones en la cuadrícula $3 \mathrm{aC}$ entre $\operatorname{los} 60$ y $90 \mathrm{~cm}$ de profundidad. Carbones de dicho sector procedentes de un fogón ubicado a $1 \mathrm{~m}$ de profundidad, asociado a tiestos cerámicos toscos, cordelería en fibra vegetal y maíz, fueron fechados en 1420 190 a.p.; la subcapa fue asignada al Formativo o "cerámico inicial" (Fernández Distel 1986) (Tabla 1).

$\mathrm{Al}$ analizar la colección detectamos que entre los 70 y $100 \mathrm{~cm}$ de profundidad se encuentran restos de frutos de Arachis sp. (maní), cordelería en fibra vegetal (incluyendo ejemplares elaborados en "charagua", Hieronymiella marginata, abundante en las cercanías del sitio) y nudos para cestería (AFD1030/IIT4528 y AFD 1037/ IIT 4518, Rolandi de Perrot y Pérez de Micou 1985). La presencia de estos nudos como forma de mantener y transportar la materia prima empleada en la elaboración de cestas, habla del proceso de manufactura y no solo del transporte del producto final, lo cual también es mencionado por las autoras antes citadas para esta capa en relación con un manojo de fibras vegetales al que le dieron varias vueltas en forma de anillo y representa, probablemente, la preparación para comenzar a realizar un cesto. Además de restos vinculados a la confección de cestería tipo coiled, y restos de este tipo de cestas, en la subcapa E1 resultaron particularmente abundantes los cordeles y sogas (algunas de estas últimas de más de $2 \mathrm{~m}$ de largo) confeccionados mayoritariamente en fibras vegetales (Fernández Distel 1981, 1986). Se menciona también para E1, cuatro fragmentos de hilados de lana de camélido, tres posiblemente de llama y uno de vicuña (Fernández Distel 1986; Rolandi de Perrot y Pérez de Micou 1985), los cuales no se hallaron en la colección. Los nudos para cestería fueron recuperados de la cuadrícula $3 \mathrm{aC}$ donde, entre 1 y $1,15 \mathrm{~m}$ de profundidad se halló el fogón del cual se obtuvo el fechado radiocarbónico ya mencionado. Restos de Prosopis nigra (IIT 4424) figuran en la colección bajo el rótulo "E2, fogón 100 cm", si bien solo en la cuadrícula 4 esta profundidad corresponde a la capa E2, no tenemos constancia de ningún fogón en la misma (Fernández Distel 1972-1989), por lo cual estos cuatro endocarpos podrían sumarse a los restos de $P$. alba (IIT 4889, un endocarpo y dos medias semillas ${ }^{2}$ ) reportados para E1 en la colección. El estudio reciente de estos restos de algarroba procurando identificar en los mismos señales de procesamiento, indican que en ambos casos hay indicios de confección de harinas y bebidas frescas y/o fermentadas a partir de los mismos, al igual que la posible presencia de formas híbridas y la exclusividad del algarrobo blanco en los restos antes mencionados (Capparelli y Lema 2011). Por lo tanto los restos asignados a una y otra subcapa tendrían rasgos en común que le darían coherencia como conjunto, a la vez que se condice con la caracterización de la subcapa E2 como sin indicios de actividades ocupacionales (ver sección siguiente). Si bien en la quebrada de Huachichocana no prosperan actualmente las especies de Prosopis que se corresponden con los denominados "algarrobo blanco" y "negro", en sectores próximos de la quebrada de Humahuaca se encuentran poblaciones de las mismas. Adyacente a este fogón (en la cuadrícula 4C) y a la misma profundidad que este, se recuperaron los entierros 5 y 6 (Figura 1b, d, Tabla 2). Se trata de dos entierros de párvulos parcialmente contenidos en piezas cerámicas, las cuales fueron encontradas muy 
próximas entre sí en una pequeña oquedad, con su apertura hacia abajo y cubriendo solo los cráneos de los restos inhumados (Fernández Distel 1981, 1986). Por debajo de un puco monocromo gris pulido (AFD 2099/ SD 45) se hallaron restos de un recién nacido y de un infante de 4 o 5 meses (entierro 5), junto a una pieza textil de malla twining, cordelería en fibra vegetal y un collar de valvas de Argopecten purpuratus del Pacífico (Fernández Distel 1981, 1986) (Tabla 2). En la colección se conserva solo el puco y el mencionado collar. Por debajo de una olla subglobular pequeña de cocción oxidante y con restos de hollín, sin asas (AFD 2101/ SD 46), se recuperaron restos de un infante de siete meses aproximadamente (entierro 6), junto a cuentas de valvas de igual origen que el collar ya mencionado y cuatro cuentas de clorita negro verdosa, determinadas por análisis específico (Fernández Distel 1981, 1986) (Tabla 2). En la colección solo se conserva la pieza cerámica y las cuentas de valvas. Ambas piezas cerámicas poseen restos de un baño de pintura roja post-cocción, la misma está por dentro y por fuera en el caso de la pieza 2101, habiéndose hallado este mismo pigmento sobre el cráneo del párvulo (Fernández Distel 1981).

\section{La subcapa E2}

De $50 \mathrm{~cm}$ de espesor aproximadamente, también se describió composicionalmente como de arena y pedregullo con abundantes restos vegetales, sin fogones, producto de la acumulación del descascarado de la cueva y sin superficies ocupacionales (Fernández Distel 1981, 1986). Corresponden a E2 dos inhumaciones: los denominados esqueleto 3 y 4 , habiéndose realizado un fechado radiocarbónico sobre un elemento de madera del ajuar del primero, el cual arrojó un resultado de 3400ะ130 a.p.; la subcapa fue asignada al "Arcaico o Precerámico Final" (Fernández Distel 1986:378) (Tabla 1). En relación a los restos vegetales y faunísticos, Arachis hypogaea se menciona para la capa E2 (Fernández Distel 1986), los restos de frutos de Arachis que se hallan en la colección (SD 216) figuran como capa E y su profundidad $(70-85 \mathrm{~cm})$ harían que la única opción viable para corroborar esta asignación de capa es que hayan sido recuperados en la cuadrícula 4 (Fernández Distel 1972-1989) ${ }^{3}$. Los restantes restos de esta especie para CHIII fueron recuperados de la capa C. En un trabajo específico A. Krapovickas (2010) -quien fuera el encargado del análisis de los restos (Fernández Distel 1981, 1986)-desestima los hallazgos más tempranos de esta cueva centrándose en los restos tardíos, por lo tanto no contamos con elementos suficientes para asegurar la procedencia de estos restos vegetales. En cuanto a los restos faunísticos, los análisis realizados por Yacobaccio y Madero (1992) para E2 -exceptuando el entierro del esqueleto 3-indican la presencia de camélidos inmaduros y maduros, en ambos casos, con representación del esqueleto axial y patas delanteras.

En cuanto a los entierros, el esqueleto 3 -cuyo ajuar destacado será abordado en una sección apartese halló articulado, decúbito lateral flectado, orientado al oeste y con la calota apoyada sobre la pared de la cueva (Fernández Distel 1986) (Tabla 2). Se trata de un individuo subadulto posiblemente masculino, de estructura muy grácil, con deformación oblicua anular poco marcada y sin afecciones dentarias (Fernández Distel 1981). Este individuo poseía el axis y la tercera vértebra cervical parcialmente soldadas debido a una sinostosis, lo cual no habría ocasionado molestias ni habría sido percibido en vida del sujeto (Mendonca en Fernández Distel 1981). El entierro 4 (Tabla 2) fue descubierto a 1 $\mathrm{m}$ del entierro 3 y en igual posición y orientación que este y también con la calota apoyando en la pared de la cueva (Fernández Distel 1981). La diferencia con el entierro 3 es la ausencia de ajuar, si bien se lo halló envuelto en hilandería de cabello humano (de dos cabos) y una pieza textil elaborada en técnica twining (Fernández Distel 1981, 1986; Rolandi de Perrot y Pérez de Micou 1985); restos mínimos de ambos se encuentran en la colección (SD 49). Según determinaciones específicas de H. Ancibor, asociados a este esqueleto se recuperaron restos de sogas (IIT 4872) cuya materia prima fueron fibras foliares de palmera y de bromeliáceas locales, pudiendo ser Tillandsia usneoides o raíces de Deuterocohnia (Fernández Distel 1986). El esqueleto 4 era un individuo masculino de unos 20 años de edad, de contextura similar al esqueleto 3 y con indicios de deformación oblicua anular más marcados, presentaba caries y -al igual que el 3- signos de abrasión dentaria (Mendonca en Fernández Distel 1981).

$\mathrm{Al}$ analizar los datos contextuales de estos dos entierros, al igual que del esqueleto 2 de la subcapa E3, vemos que poseen rangos de profundidad muy similares: el entierro 3 se ubica en la cuadrícula $3 \mathrm{aB} / 3 \mathrm{C}$ a $1,58-1,8 \mathrm{~m}$ de profundidad, el entierro 4 en la cuadrícula $2 / 3 \mathrm{C}$, entre 1,54 y $1,76 \mathrm{~m}$ de 
$\dot{6}$
$\stackrel{2}{\circ}$
$\dot{0}$
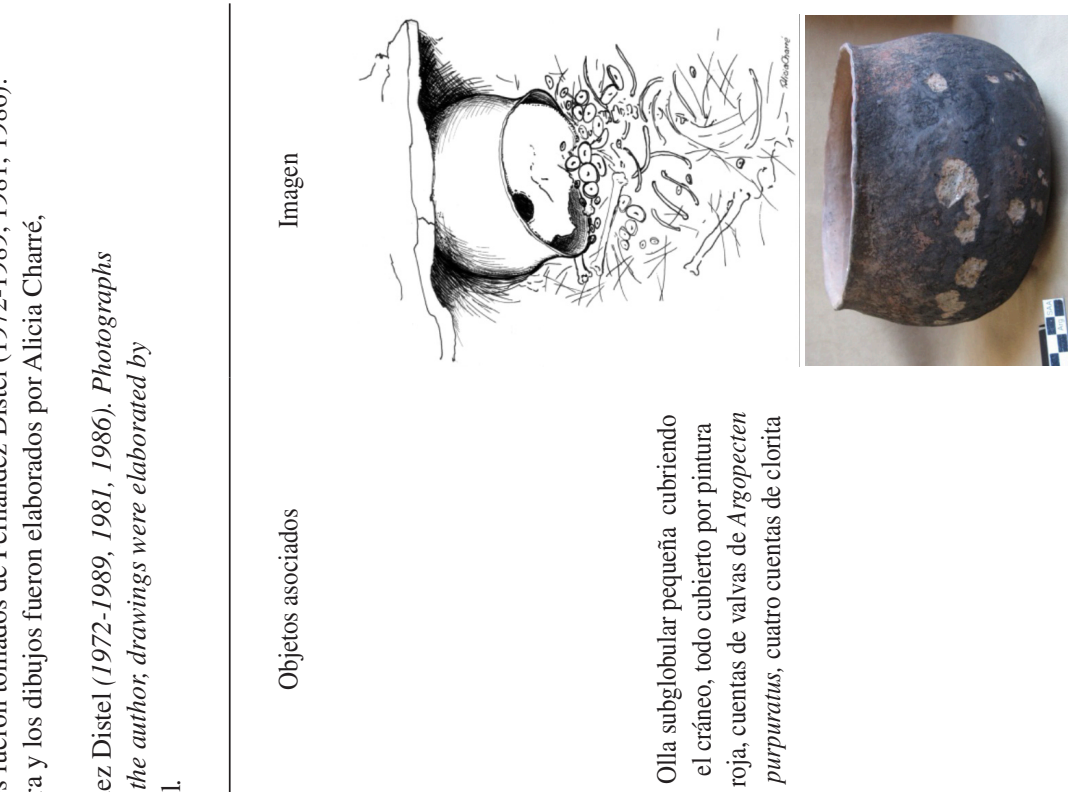

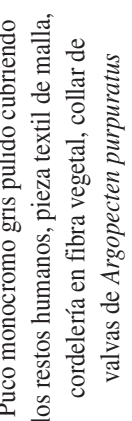

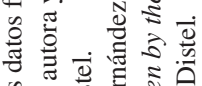

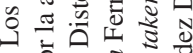

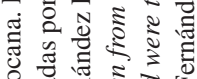

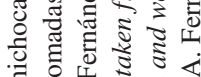

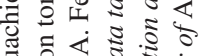

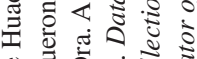
¿

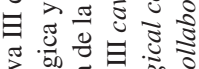

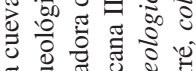

๘

ช สิ

语

ส

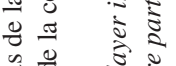

苟

की

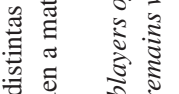

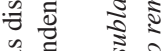

ฮี के ई

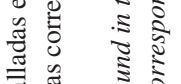

矢造

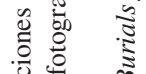

㞼

衰

$\frac{\sqrt{\pi}}{\frac{\pi}{\pi}}$

0
$\frac{0}{0}$
$\frac{\pi}{0}$
0
0
0
0
$\frac{0}{2}$
0

is

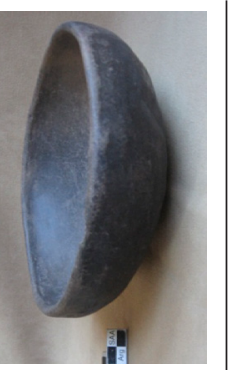

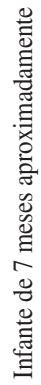

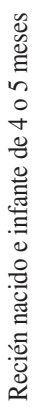

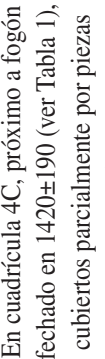

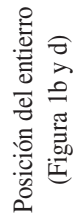

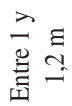

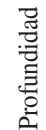

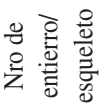

त्.
है 


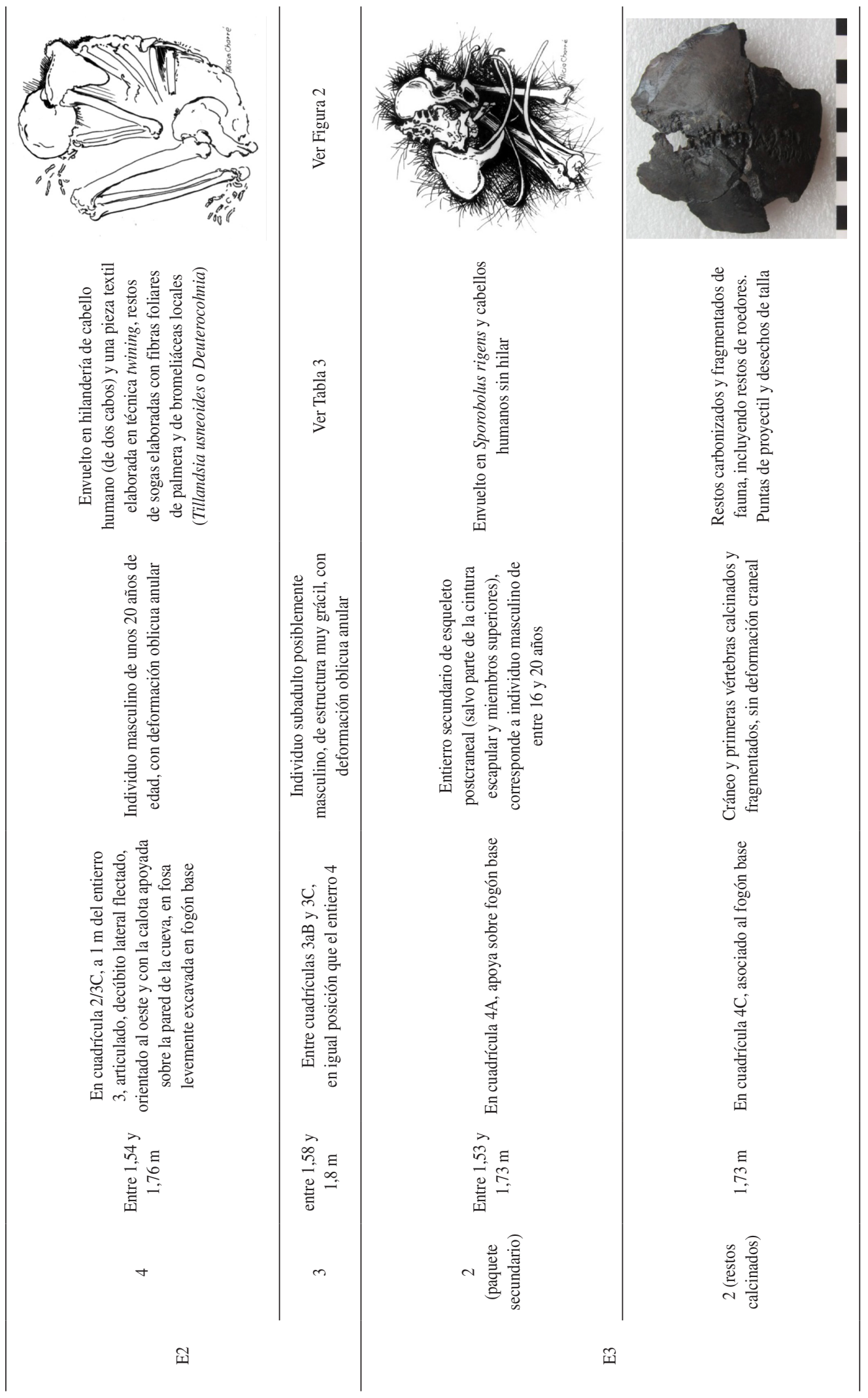


profundidad y el entierro 2 en la cuadrícula $4 \mathrm{a}$ entre los 1,53 y 1, $73 \mathrm{~m}$ (Figura 1b y d, Tabla 2). Lo primero que llama la atención es que las profundidades corresponden en los tres casos a las asignadas a la subcapa E3 (ver sección siguiente), pero teniendo en cuenta que el cero de referencia a partir del cual se computa la profundidad de los hallazgos puede discrepar entre cuadrículas (ver discusión supra), puede considerarse que estas profundidades a primera vista muy similares, no lo son tanto. Sin embargo, el análisis de los perfiles de excavación originales y la mención de que los tres entierros se hallaron apoyando en el gran fogón de base, el 3 y 4 en fosas levemente excavadas en el mismo y el 2 solo contactando (Fernández Distel 1981, 1986), nos lleva a evaluar las implicancias de la proximidad espacial entre las tres inhumaciones, la cual, claramente, no implica contemporaneidad. Teniendo en cuenta la complejidad de estos contextos, considerando la relevancia del entierro 3 y la presencia de restos de un cráneo de gran tamaño y primeras vértebras determinados como Lama glama (Yacobaccio y Madero 1992), se decidió realizar un fechado directo sobre una de dichas vértebras, el cual arrojó un resultado de $2882 \pm 43$ a.p., Arizona-20705 (1129-893 cal. a.C., 2 sigmas, Calib 704) (Tabla 1). Además de ser un aporte significativo a la cronología de las primeras formas domesticadas de llamas en la región, la proximidad de este nuevo fechado con el previamente obtenido por Fernández Distel sobre un pasivo para fuego que era parte del ajuar, ya mencionado supra, le da coherencia y confiabilidad a la inhumación como un todo (ver sección siguiente y Tabla 1). Cabe mencionar que restos del entierro 3 y 2 fueron analizados para determinar paleodieta mediante isótopos estables del carbono y nitrógeno sin que se detectaran diferencias significativas entre ambos, ya que en los dos casos se determinó una "dieta de fuentes de energía $\mathrm{C}_{4}$ y proteínas $\mathrm{C}_{3}$ La composición de recursos podría estar correspondiendo al consumo de herbívoros (principalmente, camélidos y roedores) junto a plantas CAM" (Olivera y Yacobaccio 1999:8-9).

\section{La subcapa E3}

Finalmente, esta subcapa es caracterizada como conformada por arena y pedregullo puros, con un espesor comprendido entre 1,47 y 1,8 $\mathrm{m}$ de profundidad. Cuenta con cuatro fechados radiocarbónicos realizados por Fernández Distel, tres de los cuales, junto con el hallazgo de restos de maíz, llevaron a que dicha investigadora asignara esta subcapa al "precerámico, agrícola incipiente, entre 7500 y 8200 AC" (Fernández Distel 1986:378) (Tabla 1).

Las dos muestras fechadas de mayor profundidad corresponden al denominado "fogón base" con el que se inicia la ocupación de la cueva y cuya base -a 1,8 m de profundidad en la cuadrícula 3a.Aarrojó un fechado de $9620 \pm 130$ a.p. (Fernández Distel 1986) (Tabla 1). Carbones de este fogón, deslizados en la capa estéril $\mathrm{F}$ y hallados a 2,12 $\mathrm{m}$ de profundidad en la cuadrícula $2 \mathrm{a}$ entre A y B dieron una antigüedad de $8930 \pm 300$ a.p., que luego fue corregido por laboratorio a $10200 \pm 420$ a.p. (Fernández Distel 1986) (Tabla 1). De acuerdo con la investigadora estos restos serían la "continuación del fogón del taller lítico, deslizado en capa $\mathrm{F}$ (infértil)" (Fernández Distel 1986:377). Estamos entonces ante un potente fogón asociado a un taller lítico al igual que a restos del esqueleto 2: cráneo y primeras vértebras, que fueron quemados y destruidos parcialmente en el fogón base (IIT 4841, SD 17, SD 48), en tanto el resto del esqueleto postcraneal (salvo parte de la cintura escapular y miembros superiores; IIT 4718) fueron sujetos a un entierro secundario y envueltos en paja (Sporobolus rigens o "pasto espuro", local ${ }^{4}$ ) y cabello humano sin hilar (Fernández Distel 1981, 1986) (Tabla 2). Mezclado con los restos óseos del cráneo había restos carbonizados de fauna, mayormente muy fragmentados, pudiéndose reconocer restos de roedores (SD 14). La reconstrucción del cráneo sugiere que el mismo no tenía deformación, el estudio del poscráneo indica un individuo masculino de entre 16 y 20 años (Fernández Distel 1981). El paquete secundario del esqueleto 2 se halló bajo grandes piedras y separado del sedimento de apoyo por abundante paja, por debajo de la misma una angosta camada de arena y pedregullo y por debajo, $15 \mathrm{~cm}$ de espesor de una capa de fogón que se corresponde con el fogón que se continuaba hacia el fondo de la cueva donde estaban los restos calcinados del cráneo (Fernández Distel 1972-1989).

Como mencionamos previamente, el paquete secundario del esqueleto 2 se habría recuperado en la cuadrícula 4A entre los 1,53 y 1,73 m (Figura 1b, d), Fernández Distel (1972-1989) menciona que en el sector 4C el fogón se interrumpe a los 1,73 m por una inhumación secundaria, lo cual consideramos 
corresponde a los restos calcinados de este mismo esqueleto.

Teniendo en cuenta los distintos entierros, los fechados, las indicaciones que acompañan al material de la colección, junto a notas y planillas de campo inéditas (Fernández Distel 1972-1989), podemos plantear que el fogón base estuvo entre las cuadrículas 4, 3 y 2 (en menor medida 1) y entre A, B y C, registrando su mayor potencia (aproximadamente $35 \mathrm{~cm}$ ) en $4 \mathrm{C}$ donde fue registrado entre 1,55 y $1,88 \mathrm{~m}$ de profundidad. Los restos del taller y cabezales líticos asociados a este fogón se encontraron dispersos en la cuadrícula $3 \mathrm{~B}$ y en parte $3 \mathrm{~A}$ entre 1,63 y $1,76 \mathrm{~m}$ de profundidad (Fernández Distel 1972-1989).

Según Fernández Distel $(1981,1986)$ el nivel E3 se caracteriza por la presencia de fogones. Además del fogón base, en la bibliografía y en la colección se registran fogones cuspidales a 1,47 $\mathrm{m}$ (cuadrícula 3B) y $1,53 \mathrm{~m}$ (entre las cuadrículas 2 y 3 A) y otro más profundo a $1,7 \mathrm{~m}$, este último entre las cuadrículas 2 y 3 . En la cuadrícula 3a.B a 1,53 $\mathrm{m}$ de profundidad se fechó una muestra de madera la cual dio un resultado de $8670 \pm 550$ a.p. (Tabla 1), veremos más adelante que una cesta asociada a esta muestra fue también recientemente fechada arrojando una edad mucho más moderna.

Es posible entonces que entre los $1,53 \mathrm{~m}$ y el fin de esta subcapa hubiera una sucesión de fogones con distinto grado de intensidad y de límites más o menos discretos que llevaron a caracterizarlos como fogones particulares, o bien parte de un gran área de fogón que marca el fin de los niveles fértiles, o, visto de otro modo, da inicio a las ocupaciones en la cueva III de Huachichocana.

Además de fogones y entierros, la autora también destaca a E3 respecto de las otras subcapas por la actividad de talla lítica, siendo la retalla la actividad principal. A esto se suma la presencia de tres retocadores de hueso (AFD 2582, 2583 y 849 / IIT 4446, 4442 y 4444), dos de camélido con huellas de uso y uno de cérvido (Casiraghi 1985). A su vez se recuperaron dos punzones (AFD 1072 y 2559/IIT 4438 y 4437) elaborados sobre hueso de camélido adulto y juvenil (Casiraghi 1985). Los análisis posteriores de Yacobaccio (1990) indican también actividades de mantenimiento de artefactos, que es coherente con la evidencia faunística en cuanto a actividades de caza cercanas al sitio y preparación de partes para el transporte.

En cuanto a los cabezales líticos de esta capa que se encuentran en la colección, ninguno cuenta con mayores precisiones de ubicación, salvo la señalada en la bibliografía como perteneciendo al fogón base donde se hallaron "puntas de proyectil líticas, triangulares y lanceoladas y deshechos de talla" (Fernández Distel 1986:379). El análisis de estas piezas (AFD 957/SD 39 y AFD 1063/IIT 4874-4877, AFD 958/SD 39 y AFD 2533/ IIT 4639, AFD 2560/ IIT 4638, AFD 2518 y 2519/IIT 4640lote, AFD 2561, IIT 4640, AFD 919/IIT 4878) en función de la bibliografía reciente sobre tipología de puntas líticas para sitios próximos de Jujuy y Salta (Hoguin y Restifo 2010, 2014; Restifo 2013; Restifo y Hoguin 2012) sugieren que parecerían ser coincidentes con tipologías que, a nivel regional, se han reconocido para el Holoceno Temprano y Medio. Incluso una punta de andesita (AFD 866/ SD22, n ${ }^{\circ} 15$ en fig. 11 en Fernández Distel 1986) hallada en la subcapa E1, correspondería a las tipo Tuina del Holoceno Temprano.

Además de cáscaras de huevo de Rhea pennata (IIT 4500; Fernández Distel 1981) con profundidad de entre 1,53 y $1,8 \mathrm{~m}$, los restos de fauna asignados por Fernández Distel a la subcapa E3 fueron analizados por Yacobaccio (1990) y Yacobaccio y Madero (1992). Estos investigadores señalan la preponderancia de restos de camélidos (una sola falange pudo ser determinada como guanaco, la presencia de vicuña se determinó mediante el análisis de fibras), destacándose los ejemplares inmaduros (incluyendo neonatos/nonatos, si bien pueden pertenecer a la clase menor de 22 meses), que sugieren la explotación de los mismos durante la época de nacimientos y antes de expulsar las crías del grupo familiar durante la estación húmeda. En el caso de ejemplares inmaduros se determinaron actividades de cuereo y descuartizamiento inicial con preparación de unidades manejables para transporte, siendo consumidos mayormente en el sitio; en el caso de ejemplares maduros, se plantea el ingreso de animales prácticamente enteros que fueron desarticulados en el sitio, con consumo de partes de rendimiento alto y moderado, junto a la transformación de unidades portables (Yacobaccio 1990; Yacobaccio y Madero 1992) 5 .

A partir del análisis de la colección no hemos podido definir áreas de actividad específicas asociadas a los restos faunísticos de la subcapa E3, un fechado reciente de una primera falange de guanaco adulto consignado como parte de dicho nivel (IIT 4695) arrojó un resultado de $7497 \pm 77$ a.p., Arizona 31318 (6460-6205 cal. a.C.; 2 sigmas; Calib 704) 
(Tabla 1), el cual es un tanto más tardío respecto al rango temporal que se le otorgara originalmente a esta subcapa, sugiriendo la posibilidad de sucesivas ocupaciones, quizá correlacionables con los distintos eventos de combustión mencionados previamente.

Además del hecho de poseer múltiples fogones, E3 se caracterizó por contar con restos de vegetales de cultivo en el sector cuspidal ${ }^{6}$, asociados a dos fechados procedentes de la misma cuadrícula (3a.B), uno obtenido sobre restos de maíz hallados a 1,47 $m$ de profundidad y el otro sobre un fragmento de madera hallado a 1,53 m (Tabla 1).

Los restos de maíz desecados recuperados a $1,47 \mathrm{~m}$ fueron fechados de forma directa en 1560 \pm 190 a.p. (Fernández Distel 1980a, 1986), lo cual los ubicaría en momentos formativos, tal como los restos de la capa E1 (Tabla 1). Antes de ser enviados a fechar, el análisis de los restos de maíz recuperados estuvo a cargo del Ing. J. Cámara Hernández, quien en su informe indica que, aparte de un fragmento de caña de $1,2 \mathrm{~cm}$ de diámetro, se trata de

cuatro fragmentos de $\operatorname{marlos}^{7}$ que, en general, no difieren en caracteres con los de CH III capa C. Uno de ellos, de 4,3 cm de longitud, correspondiente al ápice de la espiga y que tiene un diámetro de 11,7 $\mathrm{mm}$ en la base y $8,3 \mathrm{~mm}$ en el ápice, que poseía 10 hileras de granos que serían muy angostos y pequeños (...) El fragmento de marlo descripto últimamente y la porción de caña podrían pertenecer a un maíz con caracteres primitivos, de plantas pequeñas, cañas delgadas, con granos pequeños, seguramente duros y de marlos delgados. El resto de los fragmentos de marlos indicaría la existencia de variación en el maíz (Cámara Hernández, en Fernández Distel 1981:228).

Efectivamente, el informe señala que en la capa $\mathrm{C}$-asignada a momento inkaico- se encuentran maíces con un número de hileras de granos que va desde ocho hasta 18 , siendo más frecuentes los ejemplares de 12 y 10 hileras, estos últimos asignados a la variedad actual "Amarillo" de la Quebrada de Humahuaca, con granos duros y marlo delgado (Fernández Distel 1981). Un pequeño fragmento de marlo se conserva en la colección (SD 3) el cual, si bien no tiene claras indicaciones de procedencia, es el mismo que figura fotografiado en Fernández
Distel (1981:238) y corresponde al conjunto que se fechó de manera directa, indicándose además que el mismo no formó parte de los restos analizados por Cámara Hernández (Fernández Distel 1972-1989). La única excepción a la destrucción por fechado que menciona Fernández Distel (1981, 1972-1989) es un grano de los recuperados en la subcapa E3 durante las campaña de 1977 (en la tesis se aclara que el informe antes citado de Cámara Hernández, abarca solo lo recuperado en las campañas de 1972 y no lo que se obtuvo en las de 1976 y 1977, incluyendo más maíces de la subcapa E3), el cual poseía dos caracteres que el mencionado especialista consideró como primitivos: ser un grano de pedúnculo largo y de tamaño pequeño; si bien en la actualidad pueden encontrarse maíces con características del grano aludido (Fernández Distel 1981).

El otro fechado obtenido en la porción cuspidal de la subcapa E3 ya lo hemos mencionado, corresponde a un trozo de madera hallado en la cuadrícula $3 \mathrm{aB}$, a $153 \mathrm{~cm}$ de profundidad, el cual arrojó una antigüedad de 8670 \pm 550 a.p., indicándose como "asociación: una cesta con elementos plumarios y ajî" (Fernández Distel 1986:377) (Tabla 1). Esta cesta (AFD 2020/ IIT 4426, SD 51) fue hallada en la cuadrícula con la que se abrió la trinchera de excavación de la cueva, ampliación que llevó luego a su descubridora a asociar este hallazgo con el entierro 2 . La cesta fue recuperada entre la cuadrícula 2 y $3 \mathrm{~A}$, a 1,45 $\mathrm{m}$ de profundidad y a 1,5 m del entierro 2: "Dado que la misma [la cesta] no parece integrarse en un piso de ocupación y su hallazgo aparece un tanto desconectado del área de fogones, puede pensarse en que fuera una pieza de ajuar colocada a distancia prudencial del inhumado [ent. 2]" (Fernández Distel 1981:492). Dos fechados fueron realizados por E. Jolie (Universidad de Mercyhurst, EE.UU.) sobre restos de la cesta, los cuales son estadísticamente equivalentes: $3087 \pm 23$ a.p. UCIAMS, HC3-ND51 y HC3-4426 (1403-1218 cal. a.C., 2 sigmas, Calib 704) (Tabla 1). Estos resultados, junto a la ubicación donde fue recuperada, asocian a la cesta y a su contenido con el esqueleto 3, de hecho, se trata de una cesta de idéntica materia prima y técnica de manufactura que la hallada sobre el cráneo del mismo (Rolandi de Perrot y Pérez de Micou 1985). El contenido de la cesta consiste en un adorno de plumas de Ara militaris y vellón de lana teñido de rojo (AFD 2019), junto a restos de fruto y semillas de ají (AFD 2020/ IIT 4426 y SD55), todo coloreado levemente en rojo (Fernández Distel 1981, 1986) (Figura 2a, b y c). 
Los restos botánicos fueron considerados como C. chacoense o C. baccatum var baccatum por A. Hunziker y B. Pickersgill (Fernández Distel 1981), análisis recientes a nivel anatómico de las cubiertas seminales nos llevaron a sugerir que posiblemente se trate de la primer especie, la cual alcanza en su distribución los 2000 msm como límite superior, si bien un análisis preliminar de los restos no descarta que las plantas hayan tenido cierto grado de manejo y/o cultivo (Lema 2014).
En la sección siguiente damos un panorama pormenorizado de los restantes elementos que acompañaron a este entierro (esqueleto 3), conocido como "el chamán".

\section{“El Chamán” (Esqueleto 3)}

Al profuso ajuar que acompañaba al esqueleto 3 (Tabla 3 y Figura 2) se suma un fragmento de pericarpio de calabaza, el cual hemos determinado por

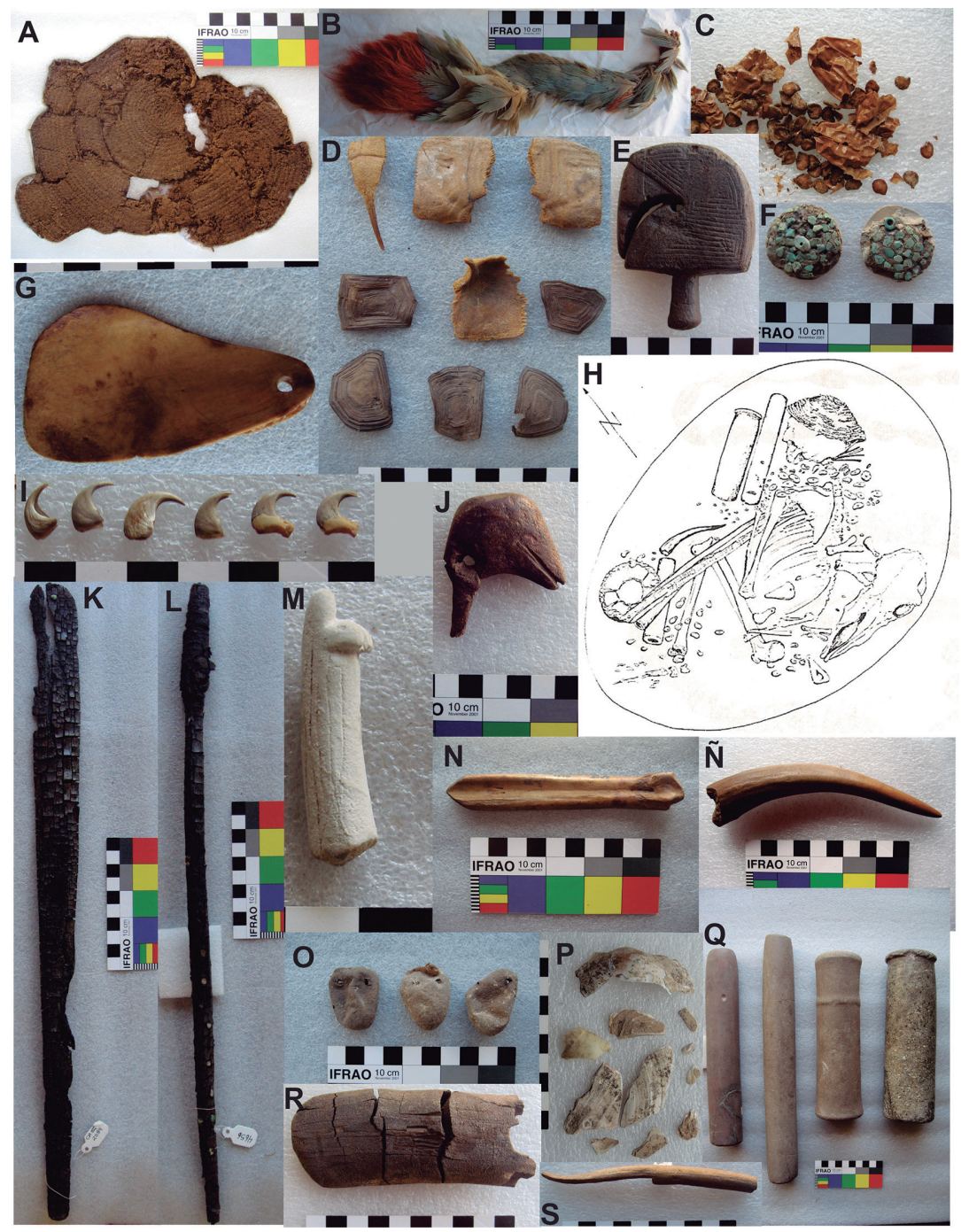

Figura 2. Acompañamiento mortuorio del entierro 3 (a) restos de cesta fechada y su contenido: artefacto de plumas y lana (b) y semillas y fruto de ají (c); (d) a (s) ver referencias en Tabla 3 salvo h que corresponde a un dibujo del entierro 3 tomado de Fernández Distel 1986.

Funerary accompaniment of burial $N^{\circ} 3$ (a) dated basketry remains and its content: artefact made of feathers and wool (b), seeds and fruit of chili pepper $(c)$; $(d)$ to $(s)$ see references in Table 3 except for $h$ which corresponds to a burial $N^{\circ} 3$ drawing taken from Fernández Distel 1986. 


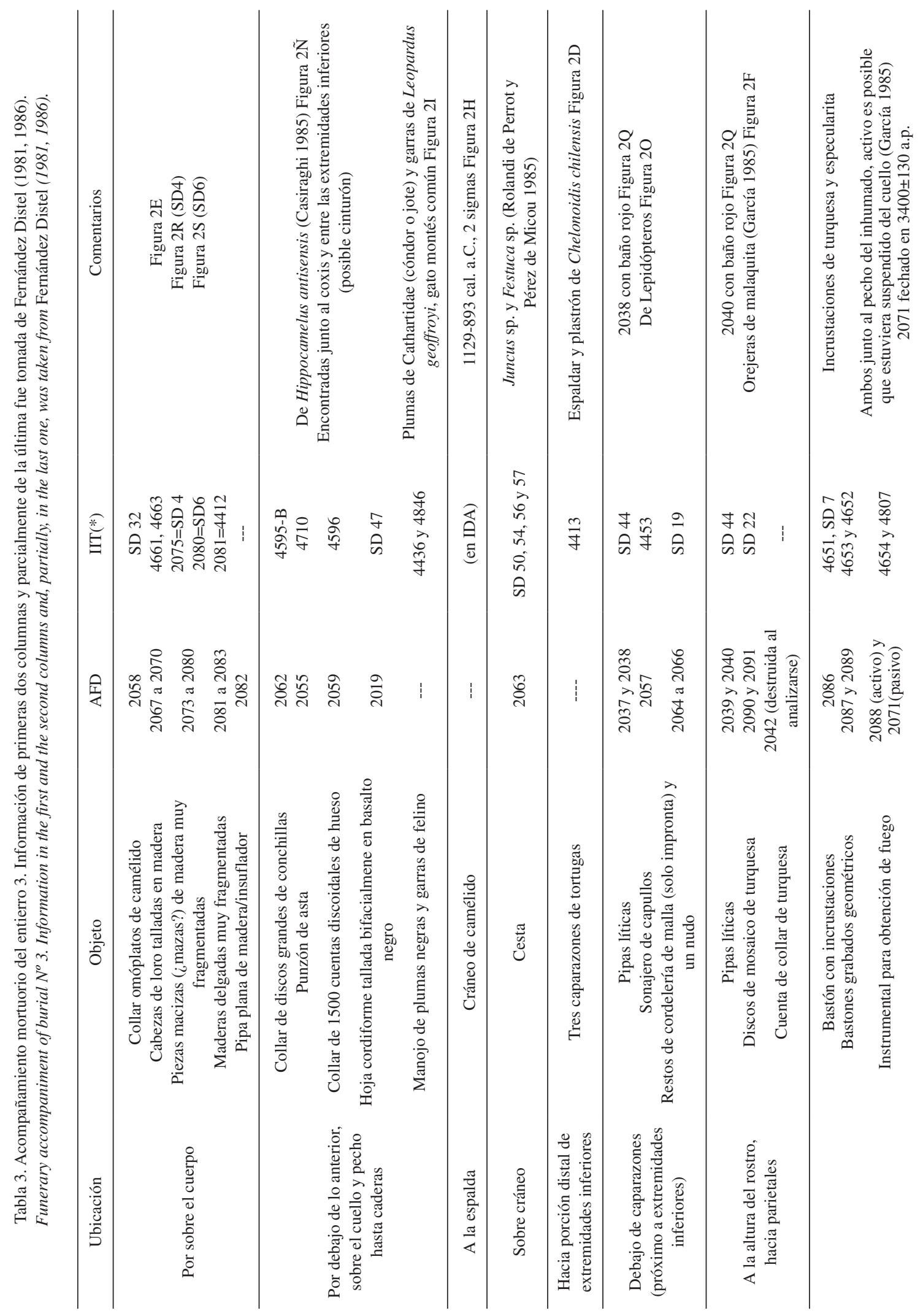




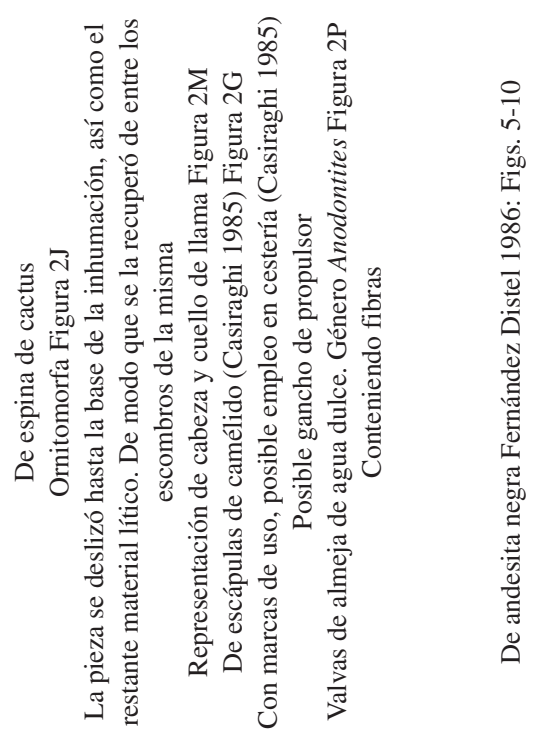

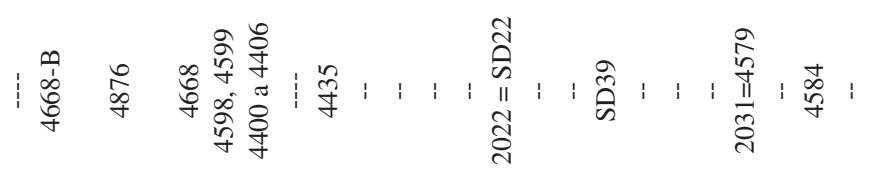

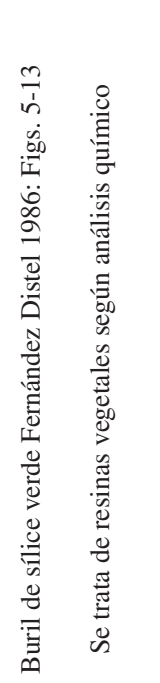

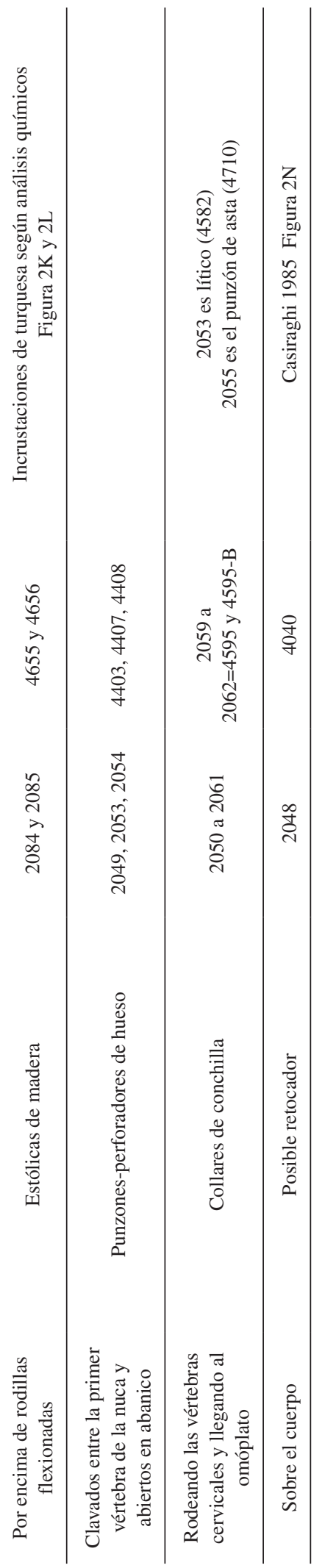

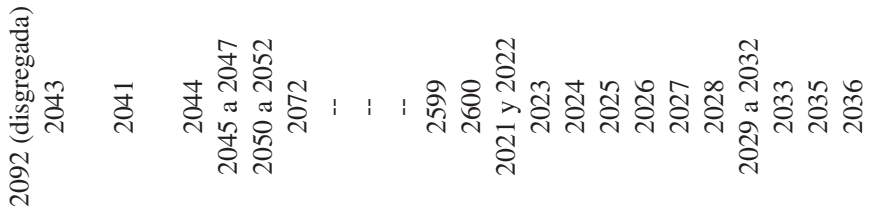

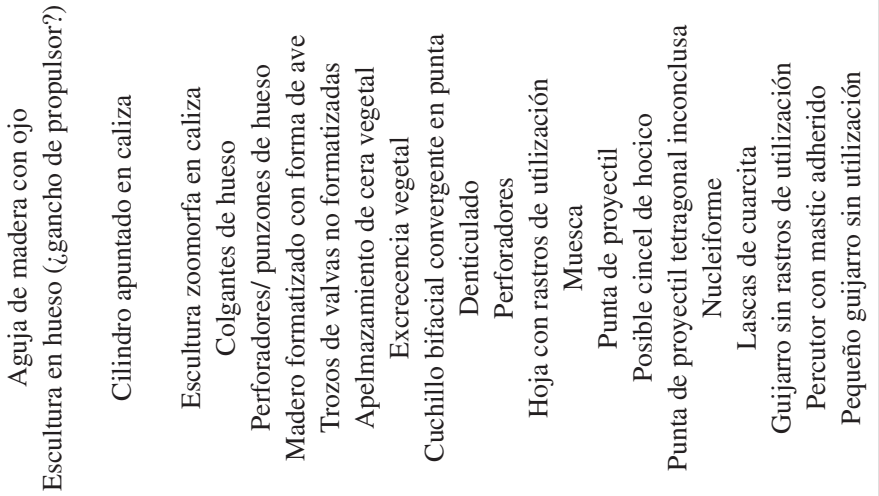
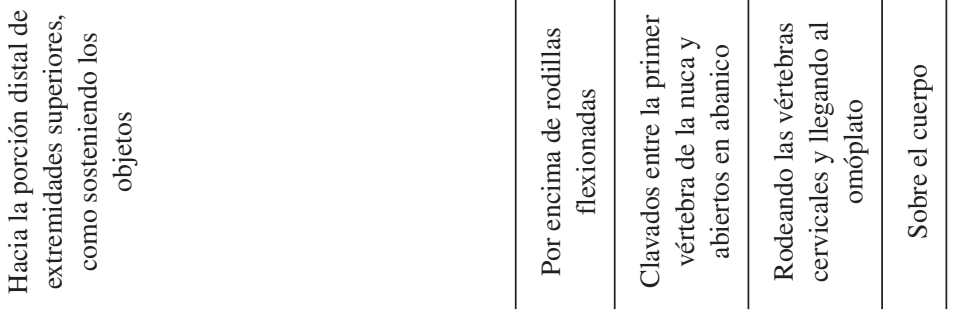
análisis anatómico como Lagenaria siceraria (AFD 2360/IIT 4624). El mismo se menciona como parte del ajuar, pero sin ubicación precisa (Fernández Distel 1981), lamentablemente el fragmento determinado no posee caracteres que permitan asignarle forma $y / o$ posible funcionalidad. Las pipas tubulares de piedra que formaban parte del acompañamiento mortuorio fueron descritas y su contenido sometido a análisis químico tras su recuperación (Fernández Distel $1980 b)^{8}$, recientemente el análisis arqueobotánico de los residuos contenidos en las pipas 2037 y 2038 indica la presencia de Anadenanthera colubrina var cebil, Trichocline sp. y Nicotiana aff. longiflora (Lema et al. 2015). Destaca en el ajuar el cráneo de llama de gran tamaño ya mencionado, junto a atlas y axis (Yacobaccio y Madero 1992), el cual está siendo estudiado actualmente, habiéndose detectado en las cervicales marcas atribuidas a la sujeción del animal por el cuello (Yacobaccio y Marcoppido 2015).

En cuanto a los restos líticos asociados a este entierro, destaca la hoja cordiforme tallada bifacialmente en andesita negra de gran tamaño (Tabla 3 AFD 2019/SD47; Fernández Distel 1981, 1986: Fig. 5-14), junto a una punta de proyectil de limbo triangular, pedunculada y elaborada en obsidiana traslúcida (Tabla 3 AFD 2025/SD 39; Fernández Distel 1981, 1986: Fig. 5-11). Un conjunto de cuatro artefactos elaborados en obsidiana traslúcida, algunos de ellos con restos de corteza (IIT 4580, 4581, 4582, 4583; Fernández Distel 1981, 1986: Fig. 5-8,7 y 4) no pudieron asociarse de manera fehaciente a un número de campo, pero son piezas asignadas por su excavadora a este ajuar. También se menciona una punta tetragonal inconclusa (Tabla 3), la cual lamentablemente no pudo ser ubicada en la colección.

Existen varios aspectos destacables del ajuar que acompaña a este individuo. A continuación nos centraremos en los restos de plantas y animales que se hallan en el mismo. Como se desprende de la Tabla 3, se trata mayormente de formas silvestres, salvo el cráneo de llama. Una representación de camélido se encuentra también en una pequeña figura realizada en caliza (Figura $2 \mathrm{~m}$ ), al igual que representaciones de loros en madera y posiblemente un pato (AFD 2072) en hueso (Figura 2e y j). Los restos de L. siceraria (mate) representarían la única forma cultivada. Considerando entonces restos óseos, de plumas, escultórica, fibras y macro y microrrestos botánicos podemos agrupar los hallazgos en taxa del altiplano y quebradas (cóndor/ jote, llama, taruca), de valles y zonas bajas de monte (mate, tortugas, ají silvestre, Nicotiana aff. longiflora, loros, lepidópteros), de yungas (cebil, guacamayo) y algunos de distribución más amplia (gato montés). En otros casos no se puede precisar la distribución debido al nivel de determinación alcanzado (pato, Trichocline sp. Anodontite). A su vez están presentes animales terrestres, aves y taxa dulceacuícolas, lo cual habla de la confluencia en este entierro no solo de pisos altitudinales distintos, sino también de ambientes diversos.

\section{Comentarios finales}

Uno de los aspectos por los cuales las ocupaciones más tempranas de la cueva III de Huachichocana fueron conocidas radicó en la asignación de especies vegetales domesticadas a las mismas. Si bien la semilla de Phaseolus vulgaris determinada por A. Burkart y E. Ulibarren (Fernández Distel 1981, 1986) se conserva en la colección (SD 2), el hecho de que la etiqueta no aporte más datos que "Capa E, $2^{\circ} 10^{\prime}$ y que en la bibliografía tampoco se den más precisiones, no permiten arriesgar una antigüedad aproximada por contexto para este resto, el cual se trataría de la variedad domesticada vulgaris. En el caso del maíz, maní y algarroba, tanto a partir del análisis de los restos presentes en la colección como del análisis de material édito e inédito, los restos del primer taxón quedaron acotados a momentos formativos o posteriores, en tanto los de maní y algarroba carecen de la precisión necesaria en la información contextual acompañante que permita asignarlos a momentos previos al Formativo. Fechados directos sobre estos restos permitirán a futuro precisar su antigüedad. Restos de frutos de mate al igual que de ají silvestre -cuyo potencial manejo o cultivo queda aún por ser estudiado y precisado en profundidad sin que se pueda aseverar por el momento- están presentes en el acompañamiento funerario del esqueleto 3, junto a restos de llama y otros animales silvestres 9 .

La ocupación de esta cueva se inició a comienzos del Holoceno con un gran fogón que, en un sector se asoció a prácticas funerarias (esqueleto 2) y en otro a actividades de talla lítica, que podría vincularse con actividades de matanza y procesamiento de camélidos silvestres durante el Holoceno Temprano. Posteriormente fueron depositados los entierros 3 y 4 , los cuales contactan con este fogón y solo 
podemos asegurar la antigüedad del entierro 3 y su acompañamiento a través de fechados consistentes entre sí. En el caso del otro enterratorio, su situación estratigráfica podría llevarnos a otorgarle igual antigüedad, el hecho de que entre los elementos asociados se hayan determinado restos de hojas de palmeras resulta coincidente con la presencia destacada de restos de tierras bajas en el ajuar del esqueleto 3. Los entierros generaron remoción de sedimentos y es posiblemente por ello que maíces de momento formativo se encontraron en niveles del Holoceno Temprano y puntas Tuina en niveles del Holoceno Tardío. Situación similar podría postularse para cabezales líticos del nivel E3 que se corresponderían con formas propias del Holoceno Medio. Tanto los fechados (Tabla 1) como el análisis de información publicada junto a registros de campo, sugieren que entre, aproximadamente, los 10000 y 7500 a.p. se produjeron probablemente ocupaciones sucesivas.

Durante el Arcaico Final (ca. 3500-3000 a.p.) el uso de la cueva fue preponderantemente funerario, en el Formativo, si bien lo fue también, hay evidencias de ocupaciones temporarias, con leves fogones, restos de consumo de alimentos, de alfarería, cordelería y actividades cesteras.
Los acompañamientos mortuorios de los infantes inhumados en el Formativo poseen elementos transcordilleranos, valvas de moluscos del Pacífico, además de elementos locales. La inhumación de "el chamán" evidencia, en cambio, restos de taxa procedentes de ambientes ecológicamente diversos y propios de la yunga, las quebradas prepuneñas y la puna, sin que se puede aseverar la presencia de elementos diagnósticos transcordilleranos.

Esperamos que análisis futuros que amplíen y profundicen los conocimientos sobre los materiales de la colección permitan enriquecer nuestra comprensión sobre el pasado de la región a partir de un registro único como el de la cueva III de Huachichocana.

Agradecimientos: Al personal del IIT, a Armando Mendoza por compartir su saber y por tener siempre la mejor predisposición, a Rodolphe Hoguin por la asistencia en consultas acerca del material lítico, a la Dra. Alicia Fernández Distel por permitirme acceder a registros inéditos de la excavación de Huachichocana III y a los evaluadores anónimos de este manuscrito, al igual que a los editores de la revista, quienes permitieron mejorar versiones previas de este trabajo. Todo lo dicho en este texto es absoluta responsabilidad de la autora.

\section{Referencias Citadas}

Aguerre, A.M., A. Fernández Distel y C. Aschero 1975. Comentarios sobre nuevas fechas en la cronología arqueológica precerámica de la provincia de Jujuy. Relaciones de la Sociedad Argentina de Antropología 9:211-214.

Capparelli, A. y V. Lema 2011. Recognition of post-harvest processing of algarrobo (Prosopis spp.) as food from two sites of Northwestern Argentina: an ethnobotanical and experimental approach for desiccated macroremains. Journal of Anthropological and Archaeological Sciences 3:71-92.

Casiraghi, M. 1985. Análisis de artefactos óseos de la cueva Huachichocana III (Provincia de Jujuy, República Argentina). Paleoetnológica IX:19-33.

Fernández Distel, A. 1972-1989. Notas de campo, perfiles y plantas de las excavaciones de la cueva III de Huachichocana. Manuscrito en posesión de la autora.

Fernández Distel, A. 1974. Excavaciones arqueológicas en la cueva de Huachichocana, Departamento de Tumbaya, Prov. De Jujuy. Argentina. Relaciones de la Sociedad Argentina de Antropología 8:101-27.

Fernández Distel, A. 1980a. Los fechados radiocarbónicos en la arqueología de la provincia Jujuy, fechas radiocarbónicas de la cueva CH III de Huachichocana, Tiuiyaco e Inca Cueva. Argentina. Radiocarbono en Arqueología 1 (4/5):89-100.
Fernández Distel, A. 1980b. Hallazgo de pipas en complejos precerámicos del borde de la puna jujeña (República Argentina) y el empleo de alucinógenos por parte de las mismas culturas. Estudios Arqueológicos 5:55-75.

Fernández Distel, A. 1981. El Período de Agricultura Incipiente en Sudamérica (los Primeros Impulsos Agriculturales en las Culturas Formativas) Representado en la Arqueología del Curso Superior de la Quebrada de Purmamarca, Jujuy. Tesis doctoral, FFyL, UBA, Buenos Aires.

Fernández Distel, A. 1986. Las cuevas de Huachichocana, su posición dentro del precerámico con agricultura incipiente del Noroeste argentino. Beitrage zur Allgemeinen und Vergleichenden Archaologie 8:353-430.

Fernández Distel, A. 1989. Una nueva cueva con maíz acerámico en el N.O. argentino: León Huasi I, excavación. Comunicaciones Científicas 1 (1):4-17.

García, C. 1985. Los instrumentales para hacer fuego del sitio Huachichocana (Depto. De Purmamarca, Pcia. De Jujuy, República Argentina). Paleoetnológica IX:13-17.

Hoguin, R. 2014. Secuencia cronológica y tecnología lítica en la Puna seca y salada de los Andes Centro-Sur para el Holoceno temprano y medio a través del ejemplo de Susques. Relaciones de la Sociedad Argentina de Antropología 39:333-364. 
Hoguin, R. y F. Restifo 2010. Tendencias tecnológicas en la transición Holoceno temprano-medio en la puna argentina: dos casos de estudio. En Arqueología Argentina en el Centenario de la Revolución de Mayo, editado por R. Bárcena y H. Chiavazza, pp. 1109-1114. Universidad de Cuyo, Mendoza.

Hoguin, F. y H. Yacobaccio 2012. Análisis lítico de ocupaciones del Holoceno Medio de Hornillos 2 (Jujuy, Argentina): discutiendo la tecnología y distribución de las puntas de proyectil "San Martín”. Chungara Revista de Antropología Chilena 44:81-95.

Lema, V. 2014. Boceto para un esquema: domesticación y agricultura tempr.ana en el Noroeste argentino. Revista Española de Antropología Americana 44:465-494.

Lema, V., D. Andreoni, A. Capparelli, G. Ortiz, R. Spano, M. Quesada y F. Zorzi 2015. Protocolos y avances en el estudio de residuos de pipas arqueológicas de Argentina. Aportes para el entendimiento de metodologías actuales y prácticas pasadas. Estudios Atacameños 51:77-97.

Olivera, D. y H. Yacobaccio 1999. Estudios de paleodieta en poblaciones humanas de los Andes del Sur a través de isótopos estables. Ponencia presentada en el $V$ Congreso Nacional de Paleopatología, Alcalá la Real, Jaen.
Restifo, F. 2013. Tecnología de caza durante el Holoceno temprano y medio en la puna de la provincia de Salta (República Argentina): patrones de variación y procesos de cambio. Comechingonia 17:59-84.

Restifo, F. y R. Hoguin 2012. Risk and technological decisionmaking during the early to mid-Holocene transition: a comparative perspective in the Argentine Puna. Quaternary International 256:35-44.

Rolandi de Perrot, D. y C. Pérez de Micou 1985. Los materiales textiles y cesteros de Huachichocana III y IV, departamento de Tumbaya, Jujuy. Paleoetnológica IX:35-41.

Yacobaccio, H. 1990. Sistemas de Asentamiento de los CazadoresRecolectores Tempranos de los Andes Centro-Sur. Tesis doctoral, FFyL, UBA, Buenos Aires.

Yacobaccio, H. y C. Madero 1992. Zooarqueología de Huachichocana III (Jujuy, Argentina). Arqueología 2:149-188.

Yacobaccio, H. y G. Marcoppido 2015. Domesticación de camélidos y patologías óseas: un caso de estudio. Trabajo presentado en las Primeras Jornadas sobre Altiplano Sur. Miradas Disciplinares, Tilcara.

\section{Notas}

1 Cabe aclarar que en ambos tipos de catalogaciones algunos números corresponden a lotes, por lo cual algunas piezas poseen igual número. Fernández Distel asignó a la mayoría de las piezas descubiertas un número de campo, que en algunos casos figura en el siglado del objeto y otras veces en las cajas que contienen a los mismos. Esta numeración también se hace presente en su tesis y publicaciones, por lo que en algunos casos se ha otorgado al material revisado el número en función del análisis bibliográfico que hemos realizado y no por estar presente el número en la colección. Este número figura antecedido por las iniciales de dicha investigadora (por ejemplo: AFD 2476).

2 Determinación del Ing. Palacios.

3 La Dra. Nurit Oliszewski me indicó la procedencia de restos de pericarpios de Arachis sp. que se encontraban en su poder, cedido años atrás por la Dra. Fernández Distel. Uno de los fragmentos está indicado como "CH III 147B Capa E 70-85 cm", misma profundidad que la indicada para SD 216.

4 Esta determinación se encuentra en Fernández Distel (1986) si bien el "espuro" o "esporal" suele ser el nombre vulgar de Pennisetum chilense.

5 En un informe elevado a la Dra. Fernández Distel en 1989, K. Graf presenta los resultados del análisis polínico llevado a cabo en varias muestras de sedimento, una de ellas se indica como "Cueva CH III 8670 BP" y posee 20\% Gramineae, $5 \%$ Compositae tubuliflorae, 20\% Labiatae o Boraginaceae,
35\% Chenopodiaceae y Amaranthaceae y 2\% Ephedra. Graf señala que "los resultados provisionales indican una estepa uniforme hace 8.500-10.000 años" siendo un clima menos cálido y húmedo que el actual.

6 Este sector cuspidal posee una concentración de lajas de las paredes de la cueva, rasgo que Fernández Distel (1986) vincula a un episodio sísmico que habría tenido lugar con posterioridad al 6000 a.C.

7 Marlo es un término que en Argentina designa al raquis de la mazorca, conocido también como coronta u olote en otros países.

8 Lamentablemente, tanto en el material édito como inédito referido a las pipas de este contexto no hemos podido encontrar datos que precisen en cuál de las cuatro pipas de piedra se realizaron los estudios químicos. Fernández Distel (1980b, 1981, 1986) menciona además una posible pipa de madera o quizá inhalador (Tabla 2) que no fue encontrado formando parte de la colección.

9 Restos de otras especies, como un tubérculo completo de Oxalis tuberosa Mol recuperado en E1 e identificado por H. Ansibor (Fernández Distel 1986) no fueron hallados en la colección. Cabe tomar en cuenta que muchas veces los restos vegetales son llevados para su determinación a los laboratorios de los especialistas y, una vez realizada la misma, no vuelven a las colecciones correspondientes, una particularidad del material arqueobotánico que suele obstaculizar el reestudio del mismo. 